Geopolítica(s) Revista de estudios sobre espacio y poder ISSN: 2172-3958

http://dx.doi.org/10.5209/GEOP.60942

\title{
La ayuda oficial al desarrollo y el contexto institucional como factores de crecimiento y progreso: casos comparados de Honduras y Costa Rica
}

\author{
Paz Benito del Pozo ${ }^{1}$ y Carolina Corcoba ${ }^{2}$
}

Resumen. La evolución de los países pertenecientes a espacios o regiones en desarrollo ofrece un cuadro de situaciones y de tendencias que ponen de manifiesto la existencia de fuertes contrastes socioeconómicos y de gobernanza entre unos y otros. En América Latina, países con características similares, localizados en una misma zona geográfica y que comparten tanto procesos históricos generadores de desigualdad (proceso colonización/descolonización), como raíces socioculturales (mundo hispánico) que actúan como elemento de identidad, muestran hoy evidentes contrastes en cuanto a modelo socioeconómico, nivel de desarrollo y oportunidades para progresar. Honduras y Costa Rica, los dos casos empíricos objeto de este análisis, ilustran situaciones de esa disparidad con resultados que permiten extraer algunas lecciones. Como premisa, se acepta que el éxito o fracaso de estos países depende del tipo de instituciones que dan soporte a su estructura política y económica, pues según sean inclusivas o extractivas pueden impulsar o bloquear el desarrollo, de acuerdo con la teoría de las élites extractivas. En este contexto, la Ayuda Oficial al Desarrollo (AOD) puede llegar a ser un factor de notable influencia, pero su eficacia dependerá de cómo se gestione por parte de las instituciones nacionales que la reciben, además de los criterios que la motivan, los sectores a los que se aplica y los intereses/implicación de los donantes. Los resultados obtenidos alumbran una realidad compleja que no contraviene los planteamientos a favor ni en contra de la AOD, lo que deja abierto el debate y pone de relieve que la explicación al desarrollo y el crecimiento desiguales de los países es multifactorial. Lo que no invalida el empeño de buscar respuestas que ayuden a comprender cada caso y facilitar la toma de decisiones.

Palabras clave: teoría élites extractivas; Ayuda Oficial al Desarrollo; Costa Rica; Honduras; desigualdad y gobernanza.

\section{[en] Official Development Assistance and Institutional Context as Factors of Growth and Progress: Comparative Cases of Honduras and Costa Rica}

\footnotetext{
Abstract. The evolution of the countries belonging to spaces or regions in development offers situations and trends that highlight the existence of strong socio-economic contrasts and of governance between one and the other. In Latin America, countries with similar characteristics, located in the

1 Grupo de investigación INVESTER, Departamento de Geografía y Geología, Universidad de León.

E-mail: paz.benito@unileon.es

2 Grupo de investigación INVESTER, Universidad de León.

E-mail: carolina.corcoba@gmail.com
} 
same geographical area and that share both historical processes that generate inequality (process colonization / decolonization) and sociocultural roots (Hispanic world) that act as an element of identity, show evident today contrasts in terms of socioeconomic model, level of development and opportunities to progress. Honduras and Costa Rica, the two empirical cases object of this analysis, illustrate situations of this disparity with results that allow get some lessons. As a premise, it is accepted that the success or failure of these countries depends on the type of institutions that support their political and economic structure, because depending on whether they are inclusive or extractive they can promote or block development, according to the Theory of the Elites Extractive. In this context, Official Development Assistance (ODA) can become a factor of influence, but its effectiveness will depend on how it is managed by the national institutions that receive it, as well as the criteria that motivate it, the sectors those that apply and the interests / involvement of donors. The results obtained illuminate a complex reality that does not contradict the proposals for or against ODA, which leaves the debate open and emphasizes that the explanation for the unequal development and growth of the countries is multifactorial. What does not invalidate the effort to seek answers that help understand each case and facilitate decision making.

Keywords: extractive elite theory; Official Development Assistance; Costa Rica; Honduras; inequality and governance.

\section{[pt] A ajuda oficial ao desenvolvimento e o contexto institucional como fatores de crescimento e progresso: casos comparados de Honduras e Costa Rica}

Resumo. A evolução dos países pertencentes a espaços ou regiões em desenvolvimento oferece um quadro de situações e tendências que enfatizam a existência de fortes contrastes socioeconômicos e de governança entre eles. Na América Latina, países com características semelhantes, localizados em uma mesma zona geográfica e que compartilham tanto processos históricos geradores de desigualdade (colonização/descolonização) como raízes socioculturais e elementos identitarios (mundo hispânico), mostram hoje notórios contastes no tocante ao modelo socioeconômico, nível de desenvolvimento e oportunidades para o progresso. Honduras e Costa Rica, os dois casos empíricos escolhidos nesta análise, ilustram esta disparidade com resultados que permitem extrair algumas lições. Como premissa, sugere-se que o êxito ou o fracasso destes países depende do tipo de instituições que oferecem suporte a sua estrutura política e econômica, pois ao serem inclusivas ou extrativas, impulsionam o bloqueiam o desenvolvimento, tal como formulado pela teoria das elites extrativas. Neste contexto, a Ajuda Oficial ao Desenvolvimento (AOD) possui uma influência importante, mas sua eficácia dependerá de como seja gerida pelas instituições nacionais que a recebem, além dos critérios que a motivam, os setores aos que se aplica e os interesses/implicação dos doadores. Os resultados obtidos revelam uma realidade complexa que não opera nem a favor nem em contra da $A O D$, deixando o debate em aberto e destacando que a explicação ao desenvolvimento e ao crescimento desigual dos países é multifatorial. Isso, contudo, não invalida o empenho em buscar respostas que ajudem a compreender cada caso e a facilitar a tomada de decisões.

Palavras-chave: teoria das elites extrativas; Ajuda Oficial ao Desenvolvimento; Costa Rica; Honduras; desigualdade e governança.

Sumario. Introducción. 1. La Teoría Institucional y la AOD: una conexión necesaria. 2. Críticas y debates sobre la AOD, su necesidad y eficacia. 3. Rasgos, evolución y contrastes de la AOD en Honduras y Costa Rica. Conclusiones. Bibliografía.

Cómo citar: Benito del Pozo, Paz \& Corcoba, Carolina (2019) "La ayuda oficial al desarrollo y el contexto institucional como facto-res de crecimiento y progreso: casos comparados de Honduras y Costa Rica”. Geopolítica(s). Revista de estudios sobre espacio y poder, vol. 10, núm. 1, 87-105. 


\section{Introducción}

El objetivo general de este trabajo es comparar dos países de América Latina con características similares y analizar por qué uno ha conseguido superar la pobreza, Costa Rica, y emprender el camino de la prosperidad, y el otro, Honduras, a pesar de compartir aspectos comunes con su vecino, está estancado y es uno de los países más pobres de la región. Para este análisis se tendrán en cuenta fundamentalmente los planteamientos teóricos de Acemoglu \& Robinson (2012), que rechazan algunas de las teorías clásicas que explican la desigualdad entre países para centrarse en la "teoría de las instituciones extractivas". La hipótesis de partida es que países que comparten una misma geografía, cultura e idioma muestran un desarrollo dispar debido a la naturaleza y comportamiento de sus instituciones. En relación con esto se analizará el papel que desempeña la Ayuda Oficial al Desarrollo (AOD) en el proceso de evolución socioeconómica y política de los países citados, y se tratará de establecer su impacto efectivo y si éste depende del factor institucional.

La metodología seguida es de tipo hipotético-deductivo, partiendo de unos planteamientos teóricos previos, para, a continuación, tratar de comprobar la validez de las hipótesis mediante un análisis empírico-comparado de indicadores socioeconómicos y de desarrollo humano en Costa Rica y Honduras. Las tareas de investigación empírica han consistido en: (a) analizar la situación de los dos países a partir de la información y los datos obtenidos en diferentes bases de datos de organismos internacionales y fuentes institucionales, para determinar su realidad geopolítica y socioeconómica; (b) analizar la AOD en los dos casos mediante el recurso a fuentes secundarias tipo libros, artículos y páginas web oficiales; y (c) establecer conexiones lógicas entre resultados parciales para llegar a un conclusión final.

\section{La teoría institucional y la AOD: una conexión necesaria}

La revisión bibliográfica sobre las últimas aportaciones teóricas al problema de la desigualdad y el desarrollo desigual nos acerca a los dos autores ya mencionados, Acemoglu \& Robinson (2012), que proponen una teoría que explica el éxito o fracaso de los países en el marco de los enfoques que recurren a las instituciones para explicar la dinámica económica a largo plazo, soslayando el determinismo geográfico y cultural de autores como Sachs (2007) o Landes (1998), respectivamente. Se trata de la denominada "teoría institucional" o "teoría de las instituciones extractivas", que pretende explicar apelando a la naturaleza y el rumbo de las diferentes instituciones políticas y económicas, el porqué de la desigualdad mundial y de la dependencia entre los países en desarrollo. Así el éxito de los países dependería del tipo de instituciones (inclusivas o extractivas) que adopten sus gobernantes. Las instituciones inclusivas son aquellas que permiten la participación de los ciudadanos en la vida pública y en la actividad económica, ofrecen un sistema jurídico imparcial y garantizan la igualdad. En los países con este tipo de instituciones existe pluralismo político y los mercados también son inclusivos (Tabla 1). En suma, se genera el llamado "círculo virtuoso de las instituciones inclusivas", por el cual "las instituciones políticas inclusivas son la base para la existencia de instituciones económicas inclusivas y viceversa, al tiempo que evitan posibles desviaciones hacia otro tipo de instituciones más restrictivas" (Acemoglu \& Robinson, 2012: 389). 
Tabla 1. Síntesis de la tesis de las instituciones extractivas sobre el éxito o fracaso de los países

\begin{tabular}{|c|c|c|c|}
\hline \multicolumn{2}{|c|}{ Instituciones inclusivas } & \multicolumn{2}{|c|}{ Instituciones extractivas } \\
\hline Políticas & $\begin{array}{l}\text { - Las instituciones políticas } \\
\text { inclusivas son aquellas plura- } \\
\text { listas, que reparten el poder } \\
\text { ampliamente entre la pobla- } \\
\text { ción y este se encuentra, a su } \\
\text { vez, centralizado. }\end{array}$ & Políticas & $\begin{array}{l}\text { - Bajo instituciones extractivas } \\
\text { el poder está concentrado en } \\
\text { manos de una élite que lo } \\
\text { ejerce sin apenas control. } \\
\text { - No hay incentivos para la } \\
\text { población. }\end{array}$ \\
\hline Económicas & $\begin{array}{l}\text { - Las instituciones económi- } \\
\text { cas fomentan la participación } \\
\text { de los ciudadanos en la acti- } \\
\text { vidad económica. } \\
\text { - Ofrecen servicios públicos a } \\
\text { la población fomentando la } \\
\text { igualdad, un sistema jurídico } \\
\text { imparcial y fomentan la pro- } \\
\text { piedad privada. } \\
\text { - Crean mercados inclusivos } \\
\text { que generan, a su vez, opor- } \\
\text { tunidades de trabajo para las } \\
\text { personas. } \\
\text { - Fomentan el desarrollo de } \\
\text { las tecnologías a través de } \\
\text { buenos sistemas educativos. } \\
\text { - Las instituciones económi- } \\
\text { cas inclusivas son las respon- } \\
\text { sables de la prosperidad de } \\
\text { los países. }\end{array}$ & Económicas & $\begin{array}{l}\text { - Los mercados bajo institu- } \\
\text { ciones extractivas solo benefi- } \\
\text { cian a un grupo reducido de } \\
\text { personas. } \\
\text { - No existe la propiedad priva- } \\
\text { da y generan pobreza entre la } \\
\text { población. } \\
\text { - La élite obtiene mayores } \\
\text { riquezas al extraer recursos del } \\
\text { resto de la sociedad. } \\
\text { - Las instituciones económicas } \\
\text { extractivas son las causantes } \\
\text { del fracaso y mayor pobreza } \\
\text { de los países. }\end{array}$ \\
\hline
\end{tabular}

Fuente: Elaboración propia a partir de Acemoglu \& Robinson (2012).

Por el contrario, las instituciones extractivas son las que están presentes en los Estados que han fracasado, debido, en parte, a que sus gobernantes han creado un sistema que enriquece y favorece a una pequeña parte de la población. El poder está controlado por una reducida élite sin límites para ejercerlo; los mercados están dirigidos y solo benefician a unos pocos; los bajos niveles educativos no permiten la innovación tecnológica $\mathrm{y}$, por lo tanto, no se crean incentivos para que la población se forme y desarrolle sus capacidades (Tabla 1). El objetivo de tales instituciones sería perpetuar el dominio de una élite todopoderosa, se trata del "círculo vicioso de las instituciones extractivas", que se retroalimenta, lo que explicaría su persistencia (Acemoglu \& Robinson, 2012: 418).

En suma, lo expuesto determinaría que "el desarrollo y la prosperidad económicas estén asociados a instituciones económicas y políticas inclusivas, mientras que las extractivas normalmente conducen al estancamiento y la pobreza" (Acemoglu \& Robinson, 2012: 115). 
Una visión crítica de esta hipótesis, que se asienta en la radical dicotomía entre instituciones extractivas e inclusivas como factor explicativo de la evolución económica y del progreso de los países, se encuentra en Alonso \& García Delgado (2014). Ambos autores centran su crítica al libro de Acemoglu \& Robinson en tres aspectos: la debilidad de la base histórica sobre la que pretenden fundamentar su teoría; la escasa importancia que se otorga a las instituciones informales y a los cambios graduales que afectan a los marcos institucionales de los países; y el limitado alcance de las consecuencias que cabe extraer de la obra. No obstante, se reconoce la notable aportación que representa dicha teoría para explicar el desarrollo y los contrastes entre países, superando el determinismo heredado de otros enfoques, como el geográfico y el cultural, también matizados por Diamond (2016).

Con respecto al papel que cumple la Ayuda Oficial al Desarrollo (AOD), es preciso citar algunos antecedentes que representan hitos en la gestación del sistema de cooperación internacional al desarrollo. Destacan, entre otros, los Acuerdos de Bretton Woods (New Hampshire, EE UU), resoluciones de la Conferencia Monetaria y Financiera de las Naciones Unidas adoptadas en julio de 1944 y que fijan las reglas para las relaciones comerciales y financieras entre los países más industrializados del mundo. En esta Conferencia se decidió la creación del Banco Mundial (BM) y del Fondo Monetario Internacional (FMI) - ambos operativos desde 1946-, así como el uso del dólar como moneda internacional. Bretton Woods trató, en suma, de poner fin al proteccionismo del período 1914-1945 (Cunega \& Ruiz Sanjuán, 2015), lo que se refuerza en 1947 con el Acuerdo Internacional sobre Aranceles de Aduana y Comercio (GATT), actual Organización Mundial del Comercio (OMC) (Fuente Pérez, 1989; López Trigal \& Benito del Pozo, 1999).

En la década de 1os 1960 ese germen institucional se densifica con las primeras agencias especializadas de cooperación al desarrollo. En 1960 se creó el Grupo de Ayuda al Desarrollo (GAD), que en 1961 se transformaría en el Comité de Ayuda al Desarrollo (CAD), el principal órgano de la Organización para la Cooperación y Desarrollo Económico (OCDE), que agrupa a los países más ricos del mundo y que se funda para alentar los esfuerzos de los países miembros a favor del bienestar económico y social de los países en desarrollo. Al CAD corresponde conseguir que dichos esfuerzos sean coordinados, integrados, eficaces y adecuadamente financiados (Calabuig Tormo \& Gómez-Torres, 2010; Cunega \& Ruiz Sanjuán, 2015).

En los años setenta la experiencia acumulada permitirá hacer balance de las actuaciones en favor de los países en desarrollo y la conclusión será que la cooperación al desarrollo no solo no ha eliminado las diferencias existentes entre el Norte y el Sur, sino que las ha acentuado. En consecuencia, las teorías desarrollistas defendidas hasta entonces se sustituyeron por las denominadas teorías ortodoxas del desarrollo económico, basadas en el enfoque de las necesidades básicas. Surge el concepto de Ayuda Oficial al Desarrollo (AOD).

Según definición adoptada en 1971, la AOD está constituida por "los flujos que las agencias oficiales, incluidos los Gobiernos estatales y locales, o sus agencias ejecutivas, destinan a los países en desarrollo y las instituciones multilaterales" (Cunega \& Ruiz Sanjuán, 2015: 35). Para que una transferencia de dinero público (de un país próspero a otro más pobre) pueda ser catalogada como AOD debe cumplir los siguientes requisitos (Cunega \& Ruiz Sanjuán, 2015: 36): 
- Los recursos aportados deben ser de origen público y tienen que dedicarse a la promoción del desarrollo económico y el bienestar social de un país en vías de desarrollo, lo que excluye otras finalidades, como las militares, y toda ayuda que sirva exclusivamente a intereses comerciales y políticos del donante.

- El país receptor de la ayuda debe constar en la relación de Estados y territorios receptores, conocida como lista del CAD38.

- La transferencia, en caso de ser un préstamo, debe poseer un grado de concesionalidad de al menos un $25 \%$. En el caso de que sea una ayuda ligada, debe ser como mínimo del $35 \%$ y si está dirigida a uno de los países menos adelantados, será al menos del 50\%.

Con el doble objetivo de impulsar, por un lado, el crecimiento y disminuir la pobreza de los países en vías de desarrollo, y, por otro, de servir de instrumento de política exterior para los donantes, la AOD no siempre fue a parar a los países más pobres y necesitados, lo que restó eficacia a sus resultados, pese a lo cual, algunos autores afirman que "se registraron resultados exitosos [...] como fue el caso de Corea del Sur en los años 1960, Bolivia y Ghana en los 1980, y Uganda y Vietnam en los 1990" (Cunega \& Ruiz Sanjuán, 2015: 38).

Tabla 2. Etapas en la evolución del sistema de AOD

\begin{tabular}{|c|c|}
\hline $\begin{array}{l}\text { Primera Etapa } \\
1950-60\end{array}$ & $\begin{array}{l}\text { - Etapa marcada por la Guerra Fría, el crecimiento de la economía mundial y } \\
\text { el proceso de descolonización, que da lugar al nacimiento de nuevos países } \\
\text { que precisan asistencia para su desarrollo. }\end{array}$ \\
\hline $\begin{array}{l}\text { Segunda Etapa } \\
\text { Década de } 1970\end{array}$ & $\begin{array}{l}\text { - Etapa caracterizada por la recesión económica mundial como consecuencia } \\
\text { de la dos crisis del petróleo. }\end{array}$ \\
\hline $\begin{array}{l}\text { Tercera Etapa } \\
\text { Década de } 1980\end{array}$ & $\begin{array}{l}\text { - Crisis de la deuda externa y adopción de los planes de ajuste estructural. } \\
\text { - Pasa a la historia como la década perdida y se constata que la AOD no había } \\
\text { sido eficaz. }\end{array}$ \\
\hline $\begin{array}{l}\text { Cuarta Etapa } \\
\text { Década de } 1990\end{array}$ & $\begin{array}{l}\text { - El mercado se presenta como única alternativa para la organización de la } \\
\text { economía y se muestra un enfoque favorable hacia la liberación de los } \\
\text { mismos. } \\
\text { - En estos años se sigue defendiendo la austeridad económica y la } \\
\text { privatización. } \\
\text { - Consecuencia de la Guerra Fría, el debate gira en torno al desarrollo y a la } \\
\text { cooperación. } \\
\text { - Se introduce el concepto de Desarrollo Humano, adoptado por el Programa } \\
\text { de Naciones Unidas para el Desarrollo (PNUD) en 1990. } \\
\text { - En el año } 2000 \text { se adoptan los Objetivos de Desarrollo del Milenio (ODM), } \\
\text { con énfasis en la lucha contra la pobreza. }\end{array}$ \\
\hline $\begin{array}{l}\text { Quinta Etapa } \\
\text { Años } 2000\end{array}$ & $\begin{array}{l}\text { - Críticas a la gestión de la AOD. } \\
\text { - Se denuncia la escasa participación de la sociedad civil en las políticas de } \\
\text { ayuda y se ponen de manifiesto las condicionalidades de la misma, sujeta a } \\
\text { intereses políticos, económicos, etc. } \\
\text { - Se acentúa la escasa rendición de cuentas que realizan los países donantes. } \\
\text { - El principal debate es sobre la eficacia de la ayuda. }\end{array}$ \\
\hline
\end{tabular}

Fuente: Elaboración propia a partir de Calabuig Tormo \& Gómez-Torres (2010). 
$\mathrm{Si}$ atendemos a las etapas de evolución del sistema de AOD que establecen Calabuig Tormo \& Gómez-Torres (2010), y cuyos rasgos se sintetizan en la Tabla 2, se aprecia que con los años ha ido cambiando la consideración que este tipo de ayuda recibe, tanto por parte de los receptores como por parte de los donantes. En los años que corresponden a la Quinta Etapa, es decir a partir del año 2000, la AOD se ha cuestionado por diferentes motivos, entre ellos la baja cuantía que los donantes dedican al desarrollo de los países del Sur (Figura 1), un débil compromiso que contraviene el Informe Pearson, publicado por el Banco Mundial (1970), que recomendaba que los países desarrollados destinasen el $0,7 \%$ de su PIB a la AOD, meta que solo seis países han alcanzado: Dinamarca, Países Bajos, Luxemburgo, Noruega, Reino Unido y Suecia; el resto de los países desarrollados ha mantenido su ayuda en alrededor del $0.3 \%$ del PIB (OCDE, 2016).

La resistencia de los países ricos a aportar ayudas de mayor cuantía, unido al contexto creado por el fin de la Guerra Fría y la consolidación de la globalización económica, hace que el foco del debate se dirija hacia la eficacia de la ayuda y, por extensión, hacia una nueva visión de su gestión (Alonso, 1999). En consecuencia, en la Declaración de París (OCDE, 2005) los países firmantes se comprometieron con acciones de largo alcance y supervisables, a fin de mejorar la eficacia de la AOD. En septiembre de 2008 en Accra (Ghana), los países desarrollados y los países en desarrollo suscribieron el Programa de Acción de Accra, centrado en el papel que ocupaban los donantes en el sistema de AOD y se instó, por un lado, a los países en desarrollo a asumir su propio desarrollo y, por otro, a los países desarrollados a contar en todo el proceso con los sistemas de gestión de los socios. Se acordó, además, una colaboración y una responsabilidad mutua entre socios y donantes (OCDE, 2008; Banco Mundial, 2008).

Figura 1. Evolución de la AOD (2000-2016)

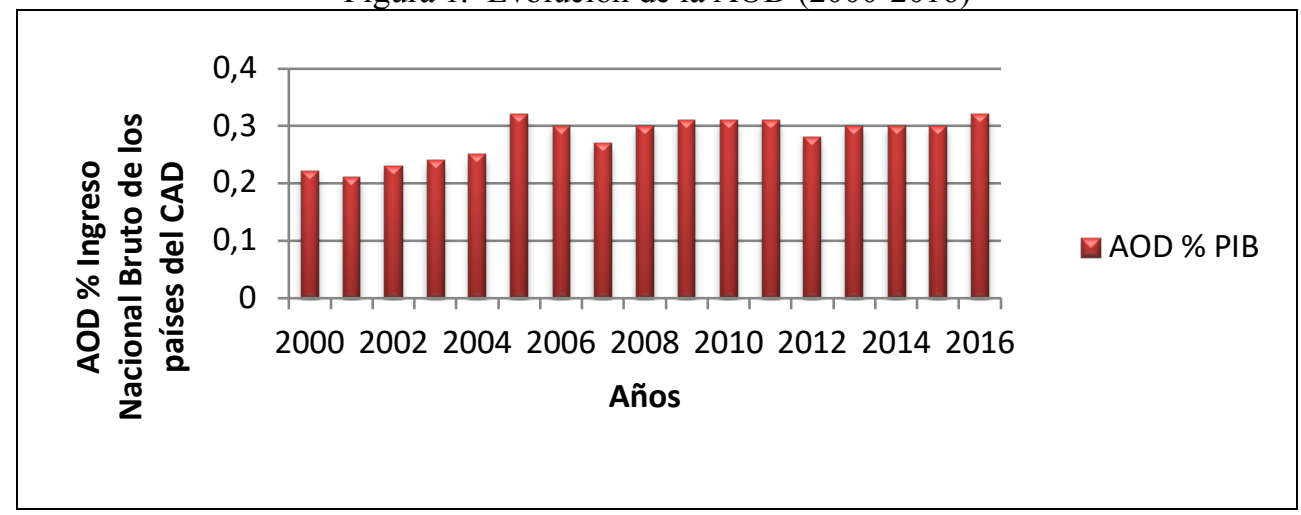

Fuente: Elaboración propia a partir de OCDE (2016) [URL: <https://data.oecd.org/oda/net-oda.htm\#indicatorchart>. Consultado el 23 de diciembre de 2018].

En definitiva, la conexión entre la AOD y la Teoría Institucional parece evidente cuando se atiende a los análisis de algunos autores que señalan que la volatilidad de la AOD es grave y aumenta con los años, y que la misma está determinada por el entorno político del país (Hudson \& Mosley, 2007). Un juicio que había sido anticipado por el informe Assessing Aid del Banco Mundial (1998) sobre eficacia de la ayuda, y corroborado poco después por Lensink \& White (1999). 


\section{Críticas y debates sobre la AOD, su necesidad y eficacia}

Con los años la finalidad de AOD experimentará cambios notables: en la década de 1960 la mayor parte de la ayuda se destinaba a infraestructuras; en los 1970 su finalidad era satisfacer necesidades básicas de la población; y en los años 1990 se orientaba a actuaciones relacionadas con la buena gobernanza, los derechos humanos y el desarrollo humano (Riddle, 2008), unos cambios de orientación que responden a las diferentes interpretaciones del desarrollo que se suceden en tan largo lapso temporal y a las alteraciones en la prioridad de los problemas que la comunidad internacional establece.

Otro rasgo susceptible de crítica es la forma en que actualmente se presta la AOD, a saber: existen multiplicidad de donantes con intereses diferentes y que financian cada vez más proyectos. Los donantes compiten entre ellos por la financiación de los proyectos, obteniendo como resultado numerosos proyectos similares y que, en ocasiones, no responden a las necesidades de la población. En esta línea, Riddle (2008) argumenta que esta heterogeneidad, tanto de financiadores como de proyectos y programas, puede ser contraproducente, e incluso obstaculizar los procesos de desarrollo de los países receptores. A esto se suma la condicionalidad, tanto de tipo político como económico, que hace que los objetivos iniciales de la AOD se alteren o desvíen a causa de intereses políticos, comerciales o geoestratégicos (Calabuig Tormo \& Gómez-Torres, 2010).

En este contexto de valoración, hay autores que se muestran a favor de la AOD y otros, más críticos, que abogan por su desaparición. En el debate teórico en torno a la AOD hay dos posiciones bien diferenciadas: la que mantienen aquellos autores que abogan por más y mejor ayuda; y la que sostienen aquellos otros que afirman que la AOD no es necesaria para que los países prosperen, que en realizada se necesita más mercado y menos ayuda.

Jeffrey Sachs (2007) reconoce que la AOD puede ser efectiva en múltiples situaciones. Algunos ejemplos de ello son la erradicación de la viruela, la revolución verde en Asia, que supuso el freno ante la posibilidad de una hambruna generalizada debido al aumento de la población, o la mejora sanitaria en atención a enfermos de VIH/SIDA en África. En este tipo de situaciones Sachs considera que la AOD, a pesar de haber sido menor de la esperada, puede ser positiva y que, efectivamente, contribuye a mejorar determinadas situaciones. Por tanto Sachs es partidario de más y mejor ayuda como una forma de combatir la pobreza. A pesar de ello, el economista se muestra crítico con el sistema de AOD y argumenta que para que los países más pobres logren mejorar su situación es necesario que los donantes cuenten con ellos en sus estrategias de desarrollo. Esto es, en lugar de conceder una suma de dinero al margen de la situación concreta del país receptor, se debería averiguar qué ayuda necesita exactamente y para qué. A partir de ahí, los países ricos deberían armonizar sus políticas de ayuda con el objetivo de crear una única estrategia de reducción de la pobreza. Para ello, Sachs propone que los países se sirvan al máximo de los organismos de Naciones Unidas en materia de desarrollo pues "garantizan un grado de especialización de vital importancia en todos los aspectos de desarrollo" (Sachs, 2007: 399).

En esa misma línea, Lensink \& White (1999) opinan que la ayuda solamente es eficaz en un entorno de políticas adecuadas. Por su parte, Paul Collier (2007) establece que la ayuda surte efectos únicamente en países bien gobernados y que la 
misma por sí sola no es eficaz y que debe acompañarse de otros instrumentos de apoyo. Collier (2007), al igual que Sachs, es partidario de una ayuda más eficaz y, para ello, es necesario considerar las necesidades concretas de los países. En suma, "la ayuda en el momento oportuno y con la finalidad oportuna puede ser muy productiva" (Collier, 2007: 192).

En el lado contrario, varios autores sostienen que la AOD no es la clave para que los países salgan de la pobreza. En esta posición destaca William Easterley (2015), que afirma que a pesar de que la AOD ha aumentado en los últimos cincuenta años, los países pobres no han salido de la pobreza, mientras que los que han crecido lo han hecho sin AOD. La tesis de Easterley (2015) parte de que la ayuda, por sí sola, no puede erradicar la pobreza, pues la única solución es el desarrollo de origen local. Defiende que el objetivo es "conseguir que las personas salgan ganando, no transformar gobiernos ni sociedades" (Easterley, 2015: 438). Desde esta perspectiva, el mundo se divide entre lo que Easterley denomina searchers y planners: los primeros luchan por ganarse la vida y cooperar a través del mercado, mientras que los segundos son los responsables de poner en marcha grandes proyectos que, empero, no resuelven problemas de fondo.

Por su parte, Dambisa Moyo (2009) considera que la AOD no solo no contribuye a que los países prosperen, sino que los atrapa en un círculo vicioso de pobreza y de dependencia, lo que a la larga se torna un lastre para crecer y prosperar. Una posición incluso más crítica es la de Eva María Durán Blanco (2008), que afirma que el único logro de la AOD ha sido convertir la pobreza en miseria y, por ello, es partidaria de que los pueblos sean autosuficientes y no dependan de la AOD. Argumenta, en este sentido, que los pueblos del Sur deben buscar su propio camino y que no se debe pensar que lo harían peor de lo que lo hicimos nosotros, los del Norte (Durán Blanco, 2008).

En definitiva, tanto los defensores de la AOD como sus detractores coinciden en afirmar que es responsabilidad de los Gobiernos de los países atrasados y empobrecidos hacer un uso adecuado de este instrumento y aplicarlo de una manera que contribuya a mejorar la calidad de vida y las oportunidades de la población, introduciendo vectores como el compromiso compartido, el desarrollo local y la sostenibilidad.

\section{Rasgos, evolución y contrastes de la AOD en Honduras y Costa Rica}

En Honduras la AOD ha evolucionado de forma muy desigual, con altibajos muy pronunciados. Destaca el periodo 2001-2005, acentuado con un fuerte descenso en el año 2003 (272 millones de dólares frente a los 563 del año 2001). A partir de ese momento los montos de ayuda continuaron bajando hasta el año 2015, que se caracterizó por una leve subida (205 millones de dólares) (Figura 2). En la evolución de la AOD hay que destacar el año 2009, marcado por la inestabilidad política y social en el país, consecuencia del golpe de Estado. Esta situación provocó el bloqueo internacional de Honduras y su expulsión temporal de algunos organismos internacionales, entre los que destacan la Organización de Estados Americanos (OEA), el Banco Mundial, el Fondo Monetario Internacional (FMI) o el Banco Centroamericano de Integración Económica (BCIE), del que Honduras fue uno de los países fundadores en 1960, con el objetivo declarado de "promover la integra- 
ción económica y el desarrollo económico y social equilibrado de la región centroamericana" 3 . Por su parte, la crisis económica mundial desencadenada en 2008 provocó que los donantes rebajasen de forma notable los flujos de ayuda al desarrollo, incluida Honduras (OCDE, 2017; Banco Mundial, 2015a; PNUD, 2017a, 2017b).

Figura 2. AOD neta recibida por Honduras (US\$ en 2015)

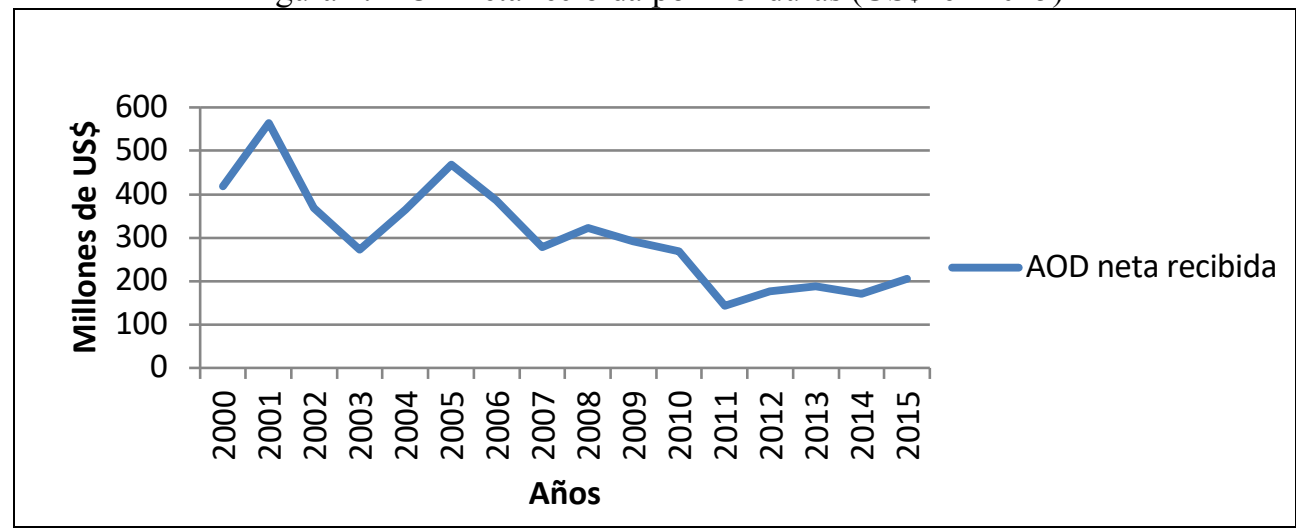

Fuente: Elaboración propia a partir de OCDE (2017) [URL: <http://stats.oecd.org/In dex.aspx?datasetcode $=$ TABLE2A\#>. Consultado el 22 de diciembre de 2018].

En relación con los principales donantes, teniendo en cuenta el Top Ten facilitado por la OCDE (2017) de países e instituciones que destinan ayuda para Honduras en el periodo 2014-2015, el principal donante multilateral es el Banco Interamericano de Desarrollo (BID), con 262 millones de dólares. En segundo y tercer lugar figuran Estados Unidos, con una contribución de 97 millones de dólares, y la Asociación Internacional de Fomento (AIF, entidad del Banco Mundial que desde 1960 presta ayuda a los países más pobres), con 90 millones de dólares.

Tabla 3. Principales donantes de AOD en Honduras (2014-2015)

\begin{tabular}{|l|c|}
\hline \multicolumn{1}{|c|}{ Países } & Millones de USD \\
\hline Banco Interamericano de Desarrollo (BID) & 262,0 \\
\hline Estados Unidos & 97,0 \\
\hline Asociación Internacional de Fomento (AIF) & 90,0 \\
\hline Unión Europea & 39,0 \\
\hline Canadá & 25,6 \\
\hline Alemania & 24,4 \\
\hline Suiza & 21,6 \\
\hline Japón & 14,9 \\
\hline España & 8,9 \\
\hline Fondo OPEP para el Desarrollo Internacional & 6,6 \\
\hline
\end{tabular}

Fuente: Elaboración propia a partir de OCDE-CAD (2017) [URL: <http://www.oecd.org /dac /financingsustainable-development/development-finance-data/>. Consultado el 17 de octubre de 2018].

3 Ver el apartado "Misión" en la web del BCIE: <https://www.bcie.org/acerca-del-bcie/informacioninstitucional/> (Consultado el 2 de febrero de 2019). 
Durante ese periodo las aportaciones de España representaron 8,9 millones de dólares, cifra que le sitúa entre los principales donantes de AOD hacia Honduras, pero que también evidencia la reducción de fondos efectuada por el Gobierno español a causa de la crisis de 2008 (Tabla 3 ).

Figura 3. AOD recibida por donante y por sector en Honduras (2015)

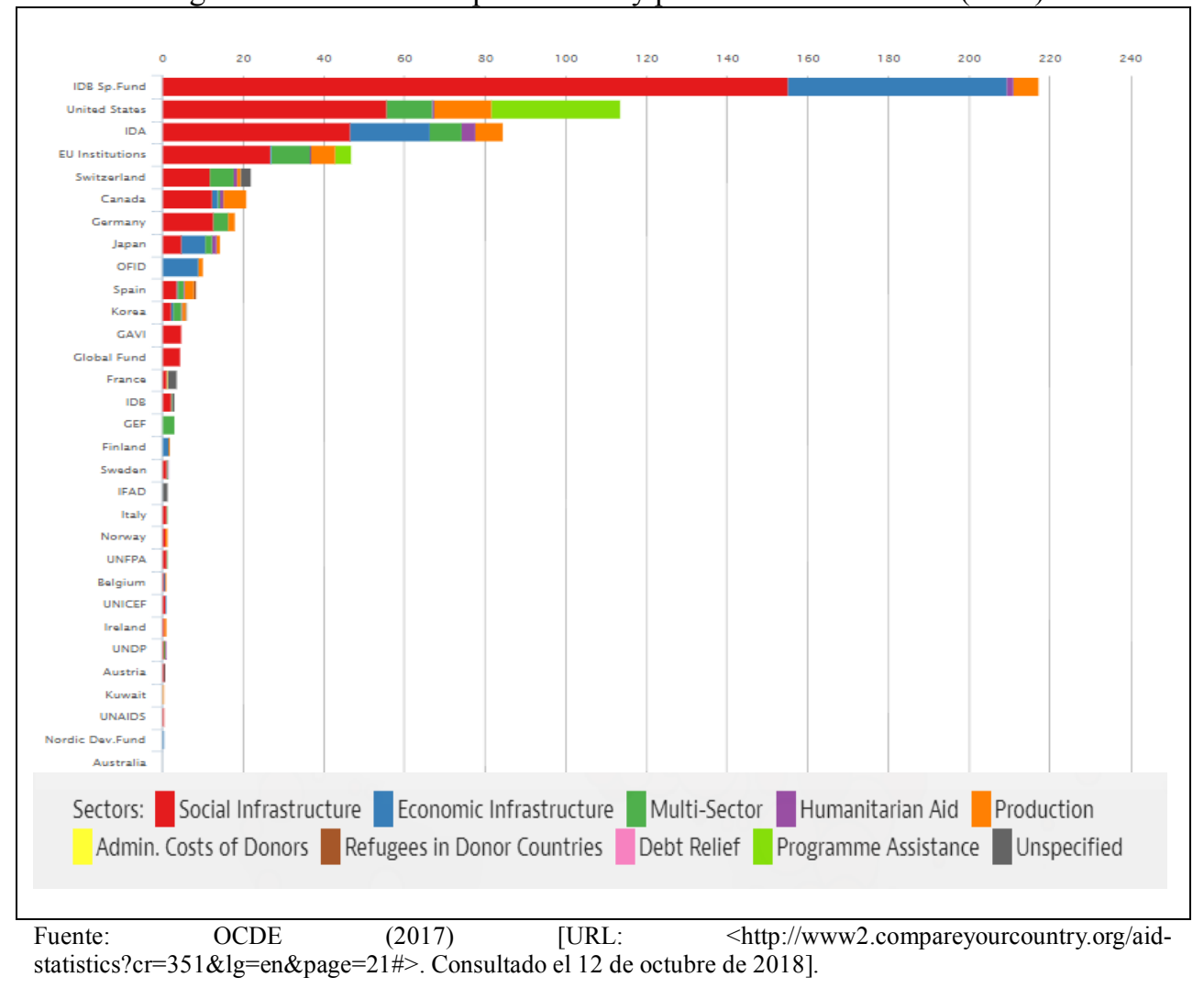

Otra parte importante de la AOD estadounidense se invirtió en diferentes Programas de Asistencia, entre los que destaca la seguridad alimentaria. El resto de los flujos, tanto de carácter bilateral como multilateral, tuvieron como principal destino Infraestructura Social, es decir, servicios sociales, servicios médicos o gestión de las finanzas públicas. Esto refleja la necesidad de mejorar aspectos esenciales para avanzar en la línea del progreso social y del crecimiento económico (Figura 3).

Por lo que respecta a Costa Rica, la evolución de los flujos de ayuda recibidos durante 2000-2015 ha sido muy fluctuante, con fuertes bajadas y subidas. Tal y como se puede comprobar en la Figura 4, desde el año 2000 la AOD proporcionada por los miembros del Comité de Ayuda al Desarrollo (CAD) de la OCDE se caracteriza por su inestabilidad. En el año 2004 el país recibe la cantidad más baja de ayuda (12,43 millones de dólares), y a partir de ahí los flujos aumentan de manera más o menos estable hasta el año 2010, cuando se aprecia un fuerte descenso. Por otro lado, en el año 2015 el país recibió el máximo de ayuda registrado en ese pe- 
riodo, con un total de 82,18 millones de dólares. La tendencia en los últimos del período considerado apunta, por tanto, hacia un aumento progresivo (Figura 4).

Figura 4. Ayuda Oficial al Desarrollo neta recibida por Costa Rica (US\$ 2015)

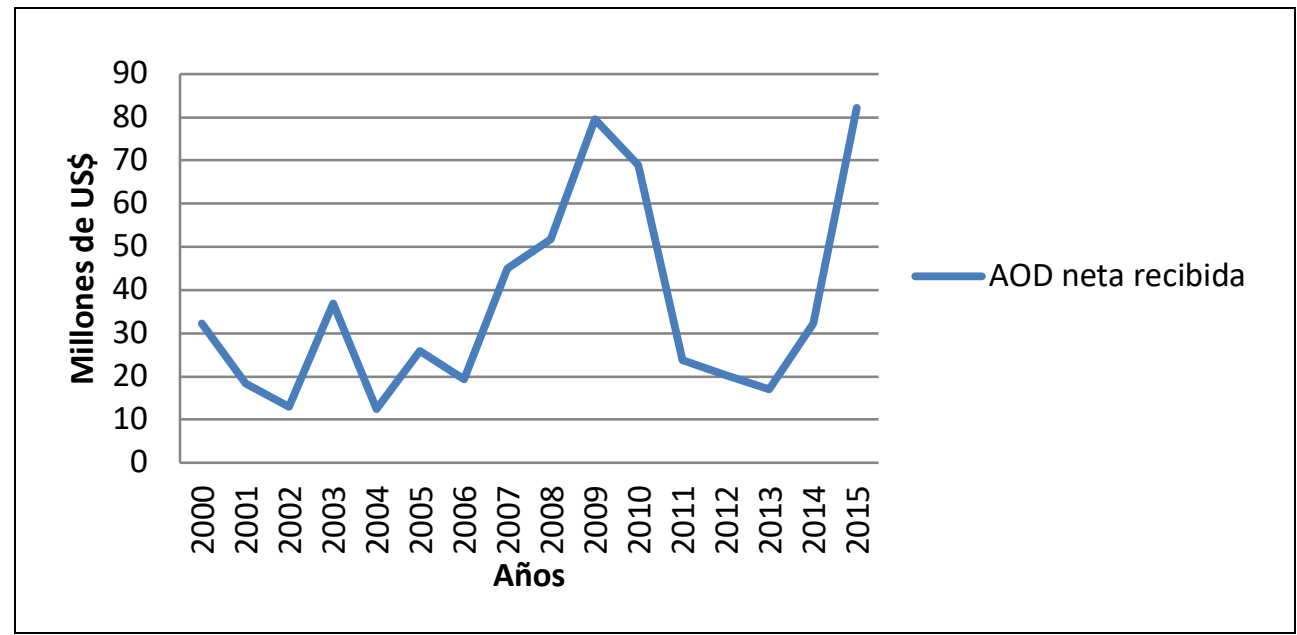

Fuente: Elaboración propia a partir de OECD.Stats [URL: <http://stats.oecd.org/ Index.aspx?datasetc ode= TABLE2A\#>. Consultado el 13 de septiembre de 2018].

En cuanto a las características de la AOD costarricense, atendiendo a los principales donantes, y teniendo en cuenta el ranking facilitado por la OCDE para el mismo periodo (2014-2015), la mayor parte de los flujos recibidos procedieron de Japón, que aportó 46,13 millones de dólares, lo que refleja la dependencia asiática de Costa Rica en esta materia. En segundo lugar se encuentra Alemania, que contribuyó con 14,7 millones de dólares, seguido por la Unión Europea, que se consagra como el principal donante multilateral con el país, con un total de 13,71 millones de dólares. España, aunque es un donante fiel de AOD a Costa Rica, se mantiene a la cola con 1,59 millones de dólares, lo que se desprende que desde la perspectiva española Costa Rica no es un país prioritario (Tabla 4).

Tabla 4. Principales donantes de AOD en Costa Rica (2014-2015)

\begin{tabular}{|l|c|}
\hline \multicolumn{1}{|c|}{ Países } & Millones de USD \\
\hline Japón & 46,13 \\
\hline Alemania & 14,70 \\
\hline Unión Europea & 13,71 \\
\hline Estados Unidos & 9,44 \\
\hline Francia & 5,35 \\
\hline Fondo para el Medio Ambiente Mundial & 4,73 \\
\hline Reino Unido & 3,88 \\
\hline Fondo Especial del BID & 2,35 \\
\hline España & 1,59 \\
\hline Corea del Sur & 1,09 \\
\hline
\end{tabular}

Fuente: Elaboración propia a partir de OCDE-CAD (2017) [URL: <http://www.oecd.org/dac/financingsustainable-development/development-finance-data/>. Consultado el 13 de septiembre de 2018]. 
La distribución de la AOD recibida, teniendo en cuenta los sectores a los que se dirige y el origen de la misma, se inclina, fundamentalmente, hacia Infraestructura Social. Así, la mayor parte de los flujos procedentes de Japón (39 millones de dólares), el principal donante, se invirtieron en este sector, mientras que los restantes se repartieron entre Infraestructura Económica y Producción. Las aportaciones de Alemania, en cambio, tuvieron una mayor repercusión en Infraestructura Económica (12 millones de dólares), aunque gran parte de sus aportaciones se invirtieron en Infraestructura Social (cinco millones de dólares). Por otro lado, en cuanto a los donantes de cooperación multilateral, la AOD procedente de la Unión Europea también se invirtió, mayoritariamente, en Infraestructura Social. El Fondo para el Medio Ambiente Mundial destinó casi la totalidad de sus aportaciones hacia el llamado Multisector, que incluye asuntos relacionados con el medio ambiente, como puedan ser la protección de la biosfera o biodiversidad (Figura 5).

Figura 5. Ayuda Oficial al Desarrollo por donantes y por sector en Costa Rica (2015)

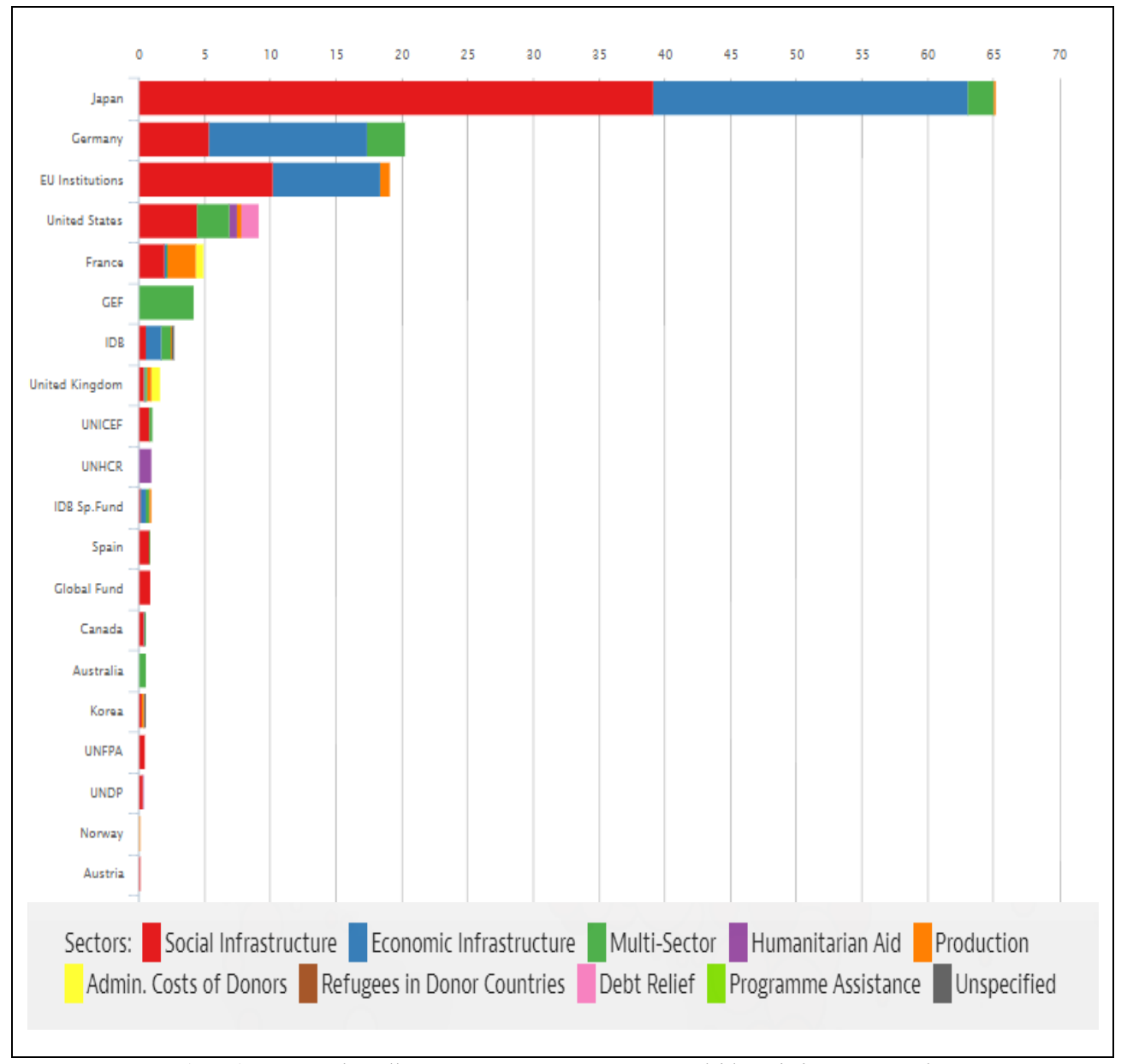

Fuente: OCDE (2017) [URL: <http://www2.compareyourcountry.org/aid-statistics?cr=336\&lg=en\&page=21>. Consultado el 13 de marzo de 2018]. 
En general, las diferencias entre el tipo y las características de ayuda que reciben ambos países no están muy acentuadas. Honduras recibe, en su mayoría, ayuda financiera de carácter reembolsable, mientras que Costa Rica es receptora de ayuda de tipo técnico. Los dos países muestran una cierta inestabilidad en los flujos de ayuda recibida acentuados por fuertes descensos en periodos o momentos concretos. Del mismo modo, Honduras y Costa Rica invierten la mayor parte de los recursos en Infraestructura Social, pero su eficacia es diferente en uno y otro país (Tabla $5)$.

Tabla 5. Diferencias y semejanzas en AOD recibida por Honduras y Costa Rica

\begin{tabular}{|l|l|l|}
\hline & \multicolumn{1}{|c|}{ Honduras } & \multicolumn{1}{c|}{ Costa Rica } \\
\hline \multirow{4}{*}{$\begin{array}{l}\text { Principales donantes } \\
\text { y distribución } \\
\text { sectorial }\end{array}$} & - Según el Top Ten de la OCDE & - Los principales donantes son: \\
& los principales donantes son: el & Japón, Alemania y la Unión \\
& BID, EE.UU y AIF. & Europea. \\
& - La mayor parte de la AOD & - La mayor parte de los flujos \\
& recibida se invirtió en & recibidos tuvieron como destino \\
& Infraestructura Social & Infraestructura Social. \\
\hline \multirow{5}{*}{ Tendencias de la AOD } & - Destaca la cooperación & \\
& reembolsable. & - Destaca la cooperación \\
& - Ayuda financiera. & reembolsable. \\
& - Tendencia decreciente desde el & - Ayuda técnica. \\
& año 2000. & - Fuerte descenso en 2004 y 2010. \\
& - Fuerte descenso en los años & - Máximo recibido en el año 2015. \\
& 2003 y 2009. & - En general, inestabilidad de la \\
& - En general, reducción de la & AOD en Costa Rica. \\
& AOD en Honduras. & \multicolumn{2}{|l}{} \\
\hline
\end{tabular}

Fuente: Elaboración propia.

Honduras se perfila, por contraste con Costa Rica, como un país perdedor $(\mathrm{Mu}-$ ñoz, 2010; Banco Mundial, 2015b). Algunas "amenazas" explican esta situación (Tabla 6). Hay que destacar, en primer lugar, la inseguridad ciudadana, unida a los altos índices de violencia que sufre el país, con una de las tasas de homicidio más elevadas y una proporción de 59 asesinatos por cada 100.000 habitantes, factor que influye de manera negativa en el progreso social. La corrupción endémica es otra traba al desarrollo que, junto con la crisis política del año 2009, provocó que los flujos de ayuda disminuyesen de forma apreciable. La fuerte dependencia de Honduras de la AOD (en torno al 80\% del presupuesto de inversión pública procede de dichos recursos, según el PNUD, 2017b) y el hecho de que la mayor parte de esa ayuda sea de tipo reembolsable es causa y efecto de sus dificultades para crecer, un círculo vicioso difícil de romper (Mulas, 2011; Pino, 2017).

Las principales fortalezas de Costa Rica en materia de desarrollo son su estabilidad política y el crecimiento económico sostenido del país . El objetivo del actual Gobierno costarricense es desarrollar procesos que sitúen al país en la esfera internacional, y en este sentido la asistencia técnica que recibe es decisiva, ya que le permite fortalecer aquellos aspectos en los que necesita un mayor apoyo. Es importante destacar los avances del país en materia de desarrollo sostenible y la ausencia de ejército, que hace que el país disponga de mayores recursos para invertir en sectores de progreso social y bienestar. No obstante, Costa Rica también afronta retos importantes en lo que a desarrollo se refiere: creciente desigualdad, caída 
sostenida del crecimiento económico, déficit fiscal relativamente alto y la reubicación de diversas empresas frenan el ritmo de crecimiento.

Tabla 6. Principales diferencias entre Honduras y Costa Rica explicativas de su desigual potencial ante el crecimiento y el progreso

\begin{tabular}{|c|c|c|}
\hline & Honduras & Costa Rica \\
\hline $\begin{array}{l}\text { A) Factor remoto de la } \\
\text { desigualdad }\end{array}$ & -Pasado colonial de esclavitud & -Pasado colonial sin esclavitud \\
\hline $\begin{array}{l}\text { B) Indicadores básicos } \\
\text { (2016) }\end{array}$ & $\begin{array}{l}\text { - PIB 19.554M euros } \\
\text {-Gasto Público 5.374M euros } \\
\text {-Gasto Defensa (\% G.P.) } 6,87 \\
\text { - IDH bajo }(0,625)\end{array}$ & $\begin{array}{l}\text { - PIB 52.227M euros } \\
\text {-Gasto Público } 10.109,8 \mathrm{M} \text { euros } \\
\text {-Gasto defensa }(\% \text { G.P.) } 0 \\
\text {-IDH alto }(0,776)\end{array}$ \\
\hline C) Tipo de instituciones & $\begin{array}{l}\text { Extractivas: } \\
\text {-El escaso crecimiento económi- } \\
\text { co no repercute en la población, } \\
\text { solo en las élites. } \\
\text {-Las políticas públicas marginan } \\
\text { sectores clave, como educación o } \\
\text { sanidad. }\end{array}$ & $\begin{array}{l}\text { Inclusivas: } \\
\text {-Apertura comercial hacia el } \\
\text { exterior. } \\
\text {-Sistema de servicios públicos } \\
\text { para los ciudadanos. } \\
\text {-Mayor bienestar general, aunque } \\
\text { muy mejorable. }\end{array}$ \\
\hline $\begin{array}{l}\text { D) Tipo de crisis econó- } \\
\text { mica }\end{array}$ & - Estructural & - Coyuntural \\
\hline $\begin{array}{l}\text { E) Ayuda Oficial al } \\
\text { Desarrollo }\end{array}$ & $\begin{array}{l}\text {-AOD de tipo financiero, reflejo } \\
\text { de la situación de crisis que } \\
\text { atraviesa el país y con un impac- } \\
\text { to difícil de determinar. }\end{array}$ & $\begin{array}{l}\text { - AOD de tipo técnico, que refle- } \\
\text { ja una situación de progreso y } \\
\text { que tiene un impacto más visible } \\
\text { y evidente. }\end{array}$ \\
\hline
\end{tabular}

Fuente: Elaboración propia con datos del y PNUD, 2015. [Datos en URL:

$<$ https://www.datosmacro.com/paises/comparar/honduras/costa-rica>. Consultado el 12 de marzo de 2018].

\section{Conclusiones}

Los resultados de la investigación demuestran que las características y las condiciones iniciales de los países de América Latina, y por extensión de otras regiones del mundo similares, no son la razón profunda de su éxito o fracaso en términos de oportunidades ante el desarrollo y el progreso general de sus sociedades. Se confirma la validez de la propuesta interpretativa de Acemoglu \& Robinson (2012), autores para los que el verdadero factor del éxito o fracaso de los países es de tipo institucional y depende de la actitud de gobernantes y responsables económicos. Construir un país de oportunidades depende, en última instancia, de las actitudes y acciones de la élite en el poder, que pueden propiciar o no el progreso y el bienestar de la población así como la eficacia del aparato del poder, tanto político como económico.

A través del análisis empírico de Honduras y Costa Rica se demuestra que ciertos antecedentes históricos condicionan o predisponen a tener instituciones inclusivas o extractivas. Así, mientras que Honduras fue un país de esclavos para la Corona española, Costa Rica no pasó por este proceso, un hecho diferencial que está en la base de la formación de instituciones generadoras de desigualdad, más en el primero que en el segundo país.

La situación de Honduras, deducida del estudio de sus indicadores socioeconómicos, es preocupante por la debilidad de sus recursos y por los bloqueos de la élite 
afianzada en el poder, más allá de que se aprecie cierta mejoría de su Índice de Desarrollo Humano (IDH) y su PIB, lo que a su vez puede atribuirse en cierta medida al flujo de recursos financieros de la AOD. Pero bajo el control de una élite extractiva este factor, la ayuda externa, tiene un alcance muy limitado: probablemente una gestión más transparente, honesta y eficaz de la AOD permitiría contrarrestar, por ejemplo, la alta exposición de Honduras a las catástrofes naturales, un fenómeno que con medios técnicos e infraestructuras adecuadas podría, si no atajarse, al menos paliarse con más éxito, ayudando a romper el círculo vicioso del fracaso y consolidar los avances logrados (Secretaría de Relaciones Exteriores y Cooperación Internacional, 2014). Ahora bien, se constata que las autoridades del país toman decisiones que no ayudan a superar los obstáculos, sino más bien a respaldar los intereses de las élites, que no apuntan en la dirección correcta para alcanzar el progreso que sí tienen otros países de la región.

Costa Rica, por su parte, cuenta con un IDH alto y con una de las tasas de pobreza más bajas de Centroamérica. En materia económica es un país de ingresos medios-altos, afectado como tantos otros por la coyuntura recesiva desencadenada en 2008, pero con capacidad demostrada para superar crisis puntuales gracias a sus políticas inclusivas, a las inversiones en servicios sociales, salud y educación en particular, y por su apertura hacia el exterior, creando importantes lazos comerciales con grandes potencias, como Estados Unidos o China, lo que refuerza su papel geopolítico en la región y en el contexto de la globalización.

Asimismo se comprueba y demuestra que el papel de la AOD no es baladí al realizar el análisis comparativo de los dos países. Mientras que Honduras recibe de los donantes ayuda de tipo financiero, que es aquella que se destina a países en situación crítica (los que precisan mejorar sus indicadores básicos en economía y bienestar), Costa Rica, recibe ayuda de tipo técnico, orientada a reforzar su proceso de consolidación económica y avance social, estando su gestión a cargo de instituciones menos corruptas y más eficaces en la defensa de los intereses generales del país que las que gestionan la ayuda hondureña.

Los resultados de esta investigación permiten afirmar que en el caso de Honduras la AOD es un instrumento de doble filo ya que, por un lado representa cerca del $80 \%$ del presupuesto de inversión pública y es clave para que el país alcance sus metas de desarrollo; pero, por otro lado, al ser una ayuda de carácter reembolsable genera unos intereses que a la larga suponen un lastre para el país, pues propician altos niveles de deuda externa. Se pone de manifiesto, así, que la AOD puede ser en sí misma un problema (y no una solución), si no se canaliza y gestiona a través de instituciones inclusivas. Y, en el caso de Honduras, la corrupción no permite pensar en una gestión honesta y provechosa.

En Costa Rica, la AOD que se recibe en forma de créditos para su economía puede crear una situación de dependencia contraproducente. Para el país puede ser más conveniente recibir exclusivamente apoyo técnico, pero esta decisión depende de los donantes, que tienen sus propios intereses. De nuevo se hace patente el difícil equilibrio entre una ayuda que da impulso y una ayuda que frena ciertas líneas de progreso.

En los dos casos analizados, el impacto de la AOD es difícil de valorar: si bien Honduras precisa de este tipo de ayuda para superar las situaciones clásicas del subdesarrollo, la debilidad institucional del país hace que la ayuda fortalezca, en cierto sentido, a la élite extractiva y sus malas prácticas. En Costa Rica, la crisis de 
los últimos años en su economía no supone un obstáculo insalvable al crecimiento general del país y los logros en materia de servicios sociales marcan la diferencia con respecto a Honduras, por lo que la ayuda técnica recibida parece ser un adecuado complemento y un apoyo a las políticas de progreso emprendidas por el Gobierno costarricense.

En términos de AOD es importante, por lo tanto, que socios y donantes trabajen de manera conjunta para valorar si efectivamente la ayuda es necesaria, qué tipo de ayuda se precisa y cuáles son las necesidades concretas que hay que atender. De la solvencia y honestidad de las instituciones de poder de cada país depende su eficacia final.

\section{Bibliografía}

Acemoglu, Daron \& Robinson, James A. (2012) Por qué fracasan los países: Los origenes del poder, la prosperidad y la pobreza. Barcelona: Deusto.

Alonso, José Antonio (1999) "La eficacia de la ayuda: crónica de decepciones y esperanzas", en J. A. Alonso y P. Mosley (eds.) La eficacia de la cooperación internacional al desarrollo: evaluación de la ayuda. Madrid: Civitas, 69-123.

Alonso, José Antonio \& García Delgado, José Luis (2014) "Acemoglu \& Robinson: por qué se empobrecen las naciones". Revista de Libros, Segunda Época, núm. 27 de mayo de 2014, 1-10.

Banco Mundial (1970) Pearson Commission Recommendations: Points of Interests. World Bank Group Archives exhibit series; núm. 030. Washington, D.C.: World Bank Group. [En línea. URL: $<$ http://documents.worldbank.org/curated/en/509101468185346260/The-PearsonCommission-July-2003>. Consultado el 15 de marzo de 2017].

Banco Mundial (1998) Assessing Aid. What Works, What Doesn't, and Why. Nueva York: Oxford University Press

Banco Mundial (2008) "Programa de Acción de Accra" [Puesto en línea el 4 de septiembre de 2008. URL: <http://siteresources.worldbank.org/ACCRAEXT/Resources /47007901217425866038/FINAL-AAA-in-Spanish.pdf>. Consultado el 20 de marzo de 2017].

Banco Mundial (2015a) "Estrategia de Asociación con el país" [URL: $<$ http://www.bancomundial.org/es/country/honduras/overview $>$ Consultado del 14 de abril de 2017].

Banco Mundial (2015b) "Marco de Alianza con el país" [En línea. URL: <http: //www.bancomundial.org/es/country/costarica $>$ Consultado de 14 de abril de 2017].

Cunega, Aram \& Ruiz Sanjuán, Sara (2015) Introducción al sistema de cooperación internacional al desarrollo. Paradigmas, actores y perspectivas. Madrid: Fundación MUSOL.

Diamond, Jared (2016) Sociedades comparadas. Barcelona: Debate.

Durán Blanco, Eva María (2008) "La gran mentira de la cooperación internacional". Rebelión. [En línea. URL: <http://www.rebelion.org/noticia.php?id=63903>. Consultado el 12 de junio de 2018].

Calabuig Tormo, Carola \& Gómez-Torres, María de los Llanos (coords.) (2010) La cooperación intenacional para el desarrollo. Valencia: Editorial de la Univèrsitat Politècnica de València. 
Collier, Paul (2007) El club de la miseria. Qué falta en los países más pobres del planeta. Barcelona: Debolsillo.

Easterley, William (2015) La carga del hombre blanco. Barcelona: Debate.

Fuente Pérez, Purificación (1989) Las instituciones supranacionales. Madrid: Akal.

Hudson, John \& Mosley, Paul (2007) Aid Volatility, Policy and Development. Sheffield Economic Research Paper Series, núm. 2007015 [En línea. URL: $<$ https://www.sheffield.ac.uk/polopoly_fs/1.105527!/file/SERP2007015.pdf $>$. Consultado el 11 de febrero de 2017].

Landes, David (1998) La pobreza y la riqueza de las naciones. Madrid: Vergara.

Lensink, Robert \& White, Howard (1999) “Assessing Aid: ¿Un manifiesto en favor de la ayuda para el siglo XXI?”. Revista ICE, núm. 778, 43-54.

López Trigal, L. y Benito del Pozo, P. (1999) Geografía Política. Madrid: Cátedra.

Moyo, Dambisa (2009) Dead Aid: Why Aid Is Not Working and How There is a Better Way for Africa. Nueva York: Farrar, Straus and Giroux. [En línea. URL: $<$ http://dambisamoyo.com/ publications-articles-videos/books/>. Consultado el $20 \mathrm{de}$ marzo de 2017].

Mulas, Carlos (2011) Corrupción, cohesión social y desarrollo: el caso de Iberoamérica. Madrid: Fondo de Cultura Económica.

Muñoz, R. S. (2010) "Estado de la Región" [En línea. URL: <http: //estadonacion.or.cr/files/bibliotecavirtual/centroamerica/004/Sierra y Muñoz 2010.pdf> Consultado el 16 de abril de 2017].

OCDE (2005) “Declaración de París sobre la eficacia de la ayuda al desarrollo". Organización para la Cooperación y el Desarrollo Económico. [En línea. URL: $<$ https://www.oecd.org/dac/effectiveness/34580968.pdf $>$ Consultado el 14 de febrero de 2017].

OCDE (2008) "Programa de Acción de Accra". Organización para la Cooperación y el Desarrollo Económico [En línea. URL: <https://www.oecd.org/dac/ effectiveness/34580968.pdf $>$ Consultado el 14 de febrero de 2017].

OCDE (2016) OECD Data. [En línea. URL: <https://data.oecd.org/oda/netoda.htm\#indicator-chart>. Consultado el 23 de diciembre de 2018].

OCDE (2017) "Compare your country. Aid statistics by donor, recipient and sector". Organización para la Cooperación y el Desarrollo Económico [En línea. URL: $<$ https://www.compareyourcountry.org/> Consultado el 23 de mayo de 2017].

OCDE-CAD (2017) Financing for sustainable development [En línea. URL: $<$ http ://www.oecd.org/dac/financing-sustainable-development/development-finance-data/>. Consultado el 19 de mayo de 2017].

Pino, Hugo Noé (2017) Deuda Pública: eso no es un problema. Instituto Centroamericano de Estudios Fiscales (ICEFI) [URL: <http://icefi.org/blog/deuda-publicaeso-no-esproblema $>$. Consultado el 1 de mayo de 2017].

PNUD (2015) Informe sobre Desarrollo Humano 2015. [En línea. URL: $<\mathrm{http}: / /$ www.undp.org /content/undp/es/home/librarypage/hdr/2015-humandevelopment-report.html>. Consultado el 15 de abril de 2017].

PNUD (2016a) Costa Rica en breve. [En línea. URL: $<$ http://www.cr.undp.org/content/costarica /es/home/countryinfo.html $>$. Consultado el 10 de febrero de 2017].

PNUD (2016b) Programa de las Naciones Unidas en Costa Rica [En línea. URL: <http: //www.cr.undp.org/>. Consultado el 19 de marzo de 2017]. 
PNUD (2017a) Las Naciones Unidas en Honduras [En línea. URL: $<\mathrm{http} / / \mathrm{hn}$.one.un.org/conten $\quad \mathrm{t} / \mathrm{unct} / \mathrm{honduras} / \mathrm{es} / \mathrm{home} /$ objetivos-del-milenio-para-eldesarrollo.html >. Consultado el 19 de marzo de 2017].

PNUD Honduras (2017b) Programa de las Naciones Unidas para el Desarrollo en Honduras [En línea. URL: //www.hn.undp.org/content/honduras/es/home/countryinfo.html>. Consultado el $21 \mathrm{de}$ marzo de 2017].

Riddle, Roger C. (2008) Does Foreign Aid Really Work? Nueva York: Oxford University Press.

Sachs, Jeffrey D. (2007) El fin de la pobreza. Cómo conseguirlo en nuestro tiempo. Barcelona: Debolsillo Editorial.

Secretaría de Relaciones Exteriores y Cooperación Internacional. República de Honduras (2014) Informe Narrativo de Metas. [En línea. URL: <http://www.sre.gob.hn /inicio/2014/agosto/INFORME\%20NARRATIVO\%20DE\%20METAS\%20\%202014.pdf $>$ Consultado el 3 de mayo de 2017].

Solana, Miguel (coord.) (2016) Espacios globales y lugares próximos. Barcelona: Icaria. 